\title{
Long-term Effects of Cholinesterase Inhibitors on Cognitive Decline and Mortality
}

Hong Xu, MD, PhD, * Sara Garcia-Ptacek, MD, PhD, * Linus Jönsson, PhD, Anders Wimo, MD, PhD, Peter Nordström, MD, PhD, and Maria Eriksdotter, MD, PhD

Neurology ${ }^{\circledR}$ 2021;96:e2220-e2230. doi:10.1212/WNL.0000000000011832

\section{Abstract}

\section{Objective}

To investigate whether cholinesterase inhibitors (ChEIs) are associated with slower cognitive decline in Alzheimer dementia and decreased risk of severe dementia or death.

\section{Methods}

Patients with Alzheimer dementia from the Swedish Dementia Registry starting on ChEIs within 3 months of the dementia diagnosis were included and compared to nontreated patients with Alzheimer dementia. In a propensity score-matched cohort, the association between ChEI use and cognitive trajectories assessed by Mini-Mental State Examination (MMSE) scores was examined with a mixed model, and severe dementia (MMSE score $<10$ ) or death as an outcome was assessed with Cox proportional hazards models.

\section{Results}

The matched cohort included 11,652 ChEI users and 5,826 nonusers. During an average of 5 years of follow-up, 255 cases developed severe dementia, and 6,055 (35\%) died. ChEI use was associated with higher MMSE score at each visit (0.13 MMSE points per year; $95 \%$ confidence interval [CI] 0.06-0.20). ChEI users had a 27\% lower risk of death (0.73, 95\% CI 0.69-0.77) compared with nonusers. Galantamine was associated with lower risk of death $(0.71,95 \% \mathrm{CI}$ 0.65-0.76) and lower risk of severe dementia (0.69, 95\% CI 0.47-1.00) and had the strongest effect on cognitive decline of all the ChEIs (0.18 MMSE points per year, 95\% CI 0.07-0.28).

\section{Conclusions}

ChEIs are associated with cognitive benefits that are modest but persist over time and with reduced mortality risk, which could be explained partly by their cognitive effects. Galantamine was the only ChEI demonstrating a significant reduction in the risk of developing severe dementia.

\section{Classification of Evidence}

This study provides Class III evidence that for patients with Alzheimer dementia ChEIs decrease long-term cognitive decline and risk of death and that galantamine decreases the risk of severe dementia.

\author{
Correspondence \\ Dr. Xu \\ hong.xu.2@ki.se
}

\section{RELATED ARTICLE \\ Patient Page \\ The Effects of Long-term \\ Medication Use in \\ Alzheimer Disease \\ Page e2247}

\section{MORE ONLINE}

$\rightarrow$ Class of Evidence

Criteria for rating

therapeutic and diagnostic studies

NPub.org/coe

\section{ค Podcast \\ Dr. Jeff Burns speaks with Prof. Maria Eriksdotter about long-term effects of cholinesterase inhibitors on cognitive decline and mortality. \\ NPub.org/fqxxkt}

\footnotetext{
*These authors contributed equally to this work.

From the Division of Clinical Geriatrics (H.X., S.G.-P., M.E.), Division of Neurogeriatrics (L.J., A.W.), Department of Neurobiology, Care Sciences and Society, and Department of Medical Epidemiology and Biostatistics (H.X.), Karolinska Institutet; Department of Internal Medicine (S.G.-P.), Neurology Section, Södersjukhuset, Stockholm, Sweden; H. Lundbeck A/S (L.J.), Copenhagen, Denmark; Department of Community Medicine and Rehabilitation (P.N.), Geriatric Medicine, Umeå University; and Theme Aging (S.G.-P., M.A.), Karolinska University Hospital, Stockholm, Sweden.

Go to Neurology.org/N for full disclosures. Funding information and disclosures deemed relevant by the authors, if any, are provided at the end of the article. 


\section{Glossary}

ChEI = cholinesterase inhibitor; $\mathbf{C I}=$ confidence interval; $\mathbf{D D D}=$ defined daily dose DOMINO-AD = Donepezil and Memantine in Moderate to Severe Alzheimer's Disease; HR = hazard ratio; ICD-10 = International Classification of Diseases, 10 revision; MMSE = Mini-Mental State Examination; $\mathbf{R C T}=$ randomized clinical trial; SveDem $=$ Swedish Dementia Registry.

The acetylcholinesterase inhibitors (ChEIs) and the NMDA receptor antagonist memantine are hitherto the only specific pharmacologic treatments approved for Alzheimer dementia, the most common type of dementia. ${ }^{1}$ Although their benefit appears to be modest, ${ }^{2,3}$ a significant body of evidence supports their effectiveness for improving cognition and their cost-effectiveness. $^{4-12}$

Degeneration of basal forebrain cholinergic neurons is one of the earliest findings in Alzheimer dementia and precedes dementia development. ${ }^{13,14}$ Progression of Alzheimer dementia is better correlated with cholinergic system dysfunction than amyloid plaque load. ${ }^{15}$ Reduction of the volume of the basal forebrain precedes changes of hippocampal volume and predicts the cortical spread of Alzheimer pathology. ${ }^{16}$

ChEIs work by maximizing the availability of endogenous acetylcholine in the brain. ${ }^{17}$ However, few randomized clinical trials (RCTs) have examined the effectiveness of ChEIs in Alzheimer dementia after 1 year of treatment ${ }^{18-22}$ or followed up patients beyond this point. ${ }^{20}$ Studies of long-term cognitive decline are difficult due to high attrition and loss to follow-up. ${ }^{20}$ Although not RCTs, follow-up of ChEI-treated Alzheimer dementia cohorts has shown small cognitive benefits at 2,3 , and $>10$ years. ${ }^{23-25}$ Moreover, a positive short-term response to ChEIs can delay nursing home placement. ${ }^{26}$ Other studies have shown associations between ChEI use and decreased risk of myocardial infarction, stroke, and death in patients with dementia. ${ }^{27-30}$

We conducted a longitudinal cohort study on the Swedish Dementia Registry (SveDem) to investigate whether the cognitive benefit of ChEIs in routine settings persists over the long term and whether ChEI use is associated with decreased risk of severe dementia and death.

\section{Methods}

\section{Study Design and Data Source}

The longitudinal cohort study includes patients with incident diagnosed dementia registered in the SveDem (svedem.se). SveDem is a web-based registry established in 2007 with the aim of registering all patients with incident dementia in Sweden and following them up annually. ${ }^{12,31,32}$ The baseline registration in SveDem is initiated at the time of the dementia diagnosis. The majority of patients are diagnosed and thus registered in a mild stage of dementia, but some patients do have an advanced dementia by the time they seek care and are thus diagnosed in a more advanced stage. The registry stores data on demographics, cognitive evaluation by Mini-Mental
State Examination (MMSE), the type of dementia, and pharmacologic management. SveDem was merged with the National Patient Registry to include diagnoses made in specialist clinics and hospitals, the Prescribed Drug Registry, and the Total Population and Causes of Death Registry.

\section{Standard Protocol Approvals, Registrations, and Patient Consents}

The regional human ethics committee in Stockholm approved the study (dnr 2017/501-31). Patients are informed about registration in SveDem at the time of their dementia diagnosis. The aim of SveDem is to improve dementia treatment and care. Patients can refuse registration, obtain information on their registration any time, and withdraw consent at a later date. Any research project on SveDem data must be approved by the ethics committee. Signed consent for research, however, was not required for this study in accordance with the protocol submitted and approved by the ethics committee. Data were deidentified by Swedish authorities before delivery to the research team.

\section{Study Population}

From 2007 to 2017, 78,346 patients with dementia were registered in SveDem; in these patients, the most common dementia types were Alzheimer dementia (31\%) and mixed Alzheimer dementia (19\%), followed by unspecified dementia (23\%), vascular dementia (19\%), Lewy body dementia (2\%), frontotemporal dementia (2\%), Parkinson disease with dementia (2\%), and other (2\%). In the present study, we included all patients with incident diagnosed Alzheimer dementia or mixed Alzheimer dementia $(n=39,196)$. We defined the study inclusion date as the date of the dementia diagnosis in SveDem, the date when the patient started ChEI, or the first date on which a dementia diagnosis appeared in the National Patient Registry (whichever came first). We excluded patients if data were missing on age, sex, diagnosis, or MMSE score at baseline $(\mathrm{n}=1,533)$. We excluded patients with baseline MMSE score $<10(\mathrm{n}=789)$ because the indication for initiating ChEIs in Sweden is mild to moderate Alzheimer dementia (MMSE score $\geq 10$ ). Finally, we excluded patients with a first prescription date of ChEI treatment $>3$ months from the baseline MMSE $(n=5,808)$ to ensure that the MMSE score was representative of the cognitive status at the start of ChEI treatment and to avoid increasing confounding by indication (figure 1). The majority (93.4\%) started treatment with ChEIs on the same day of the MMSE measurement or after, while 765 (6.6\%) patients were on ChEI treatment before the baseline MMSE test was performed. In Sweden, MMSE or a similar screening test is recommended when diagnosing dementia but is not required for ChEI prescription..$^{33} \mathrm{~A}$ total 31,054 patients 


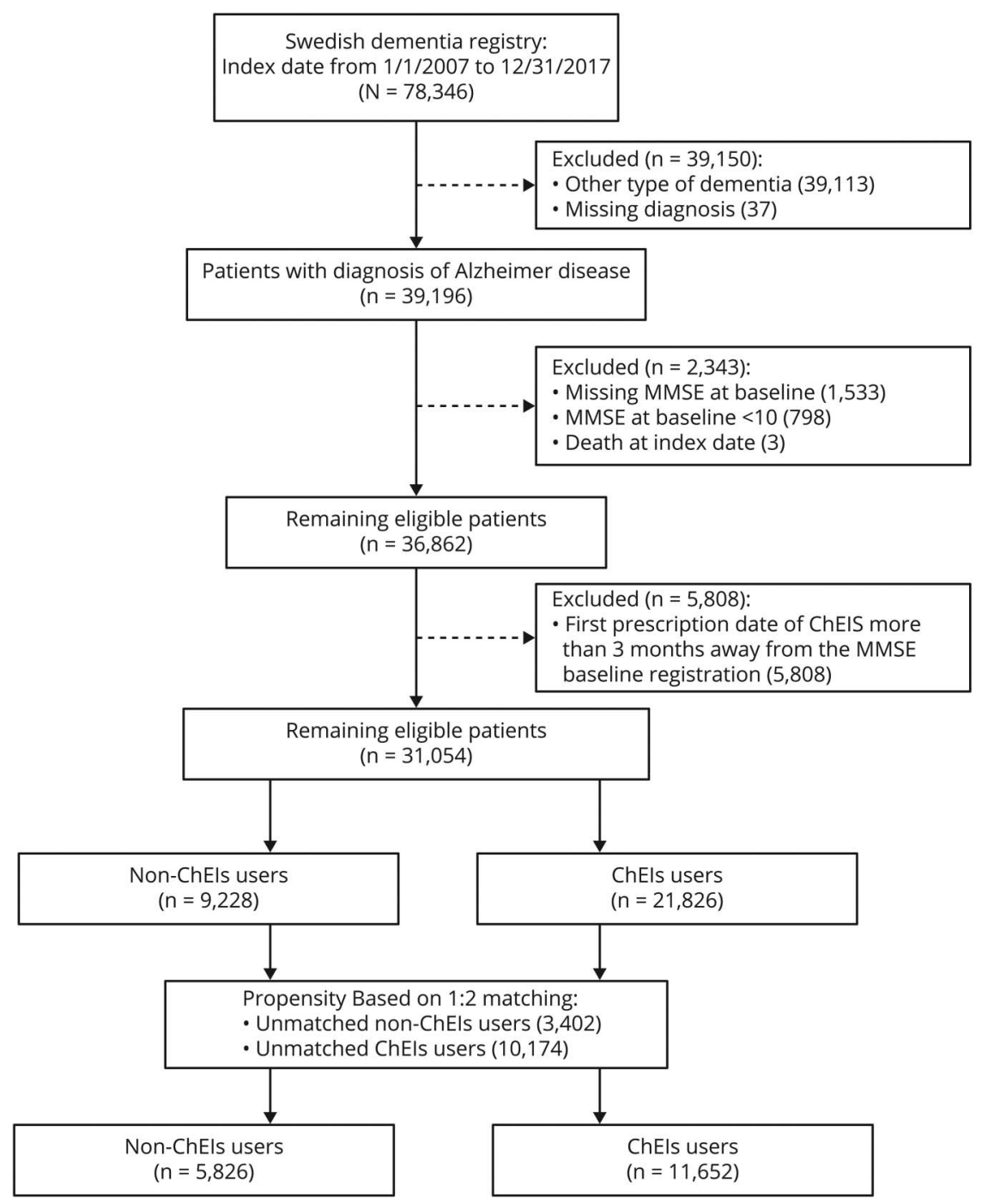

ChEl $=$ cholinesterase inhibitors; $\mathrm{MMSE}=$ MiniMental State Examination. with Alzheimer dementia were eligible, comprising 21,826 ChEI users and 9,228 nonusers.

\section{ChEl Exposure}

ChEI treatment (donepezil, rivastigmine, and galantamine) was defined as ChEI initiation within 3 months of the dementia diagnosis (ChEI use) (table e-1, doi.org/10.5061/dryad. 2jm63xsmz). Patients who started ChEI after this initial 3-month period were excluded from analyses (figure 1). Nonusers were defined as never being treated with ChEIs during the duration of the follow-up period. In our main analysis, the exposure was assumed to be constant. This was a conservative design, attempting to limit the confounding that could occur if the patient's rate of cognitive decline influenced treatment status after initiation, imitating the intention-to-treat design of clinical trials.

We collected information on the doses of each dispensation of ChEIs over the initial 3-month period. ChEI doses were expressed as the number of defined daily doses (DDDs) present in each package or dispensation. The DDD for each drug is set by the World Health Organization and is, by definition, the "assumed average maintenance dose per day for a drug used for its main indication in adults." 34 To simplify comparisons, we summed the total number of DDDs dispensed during the initial 3-month period and averaged this number out over the number of days to obtain the average DDD per day. For reference, the DDD of donepezil is $7.5 \mathrm{mg}$, of rivastigmine is $9 \mathrm{mg}$ (oral) or $9.5 \mathrm{mg}$ (transdermal), and of galantamine is $16 \mathrm{mg}$. If multiple ChEIs were used, their DDDs were summated. For example, in clinical practice, we may start donepezil at a low dose of $5 \mathrm{mg}$; after 4 weeks, if tolerated, the dose is increased to $10 \mathrm{mg}$. For such a patient, the average DDD would be $8.3 \mathrm{mg}$ after 3 months: ([5mg $\times 7$ days $\times 4$ weeks $]+[10 \mathrm{mg} \times 7$ days $\times 8$ weeks $]) /(7$ days $\times 12$ weeks $)$.

\section{Covariates}

Covariates were defined at the date of study entry and included age, sex, comorbid conditions (hypertension, diabetes, history of myocardial infarction, congestive heart failure, 
peripheral vascular disease, cerebrovascular disease, chronic pulmonary disease, chronic kidney disease, cancer, atrial fibrillation), and medications (angiotensin-converting enzyme inhibitors, angiotensin receptor blockers, $\beta$-blockers, calcium channel blocker, statins, antipsychotics, antidepressants). The definition of comorbid conditions was based on ICD-10 code. ${ }^{35}$ Diabetes and hypertension were in addition enriched with information on purchase of related medication up to 3 years before study entry date through the use of the Anatomical Therapeutic Chemical code A10 for antidiabetics. The ICD and Anatomical Therapeutic Chemical codes are detailed in table e-1 (doi.org/10.5061/dryad.2jm63xsmz).

\section{Outcomes}

Baseline and follow-up MMSE scores were obtained from SveDem. Severe dementia was defined as MMSE score $<10$ during follow-up. ${ }^{36}$ The occurrence of death was obtained from the Total Population and Causes of Death Registry. Patients were followed up from study entry until the event of interest, death, or end of follow-up (October 16, 2018), whichever occurred first.

\section{Data Analysis}

Propensity score matching was performed to balance confounders between ChEI users and nonusers. Using logistic regression models, we estimated the propensity score to receive ChEI treatment based on age, sex, baseline MMSE score, comorbid conditions, and medications. We performed 2:1 propensity score matching to pair each ChEI user to a nonuser without replacement by the nearest number matching and with a caliper of 0.01 .

The cognition trajectories (MMSE score change) between ChEI users and nonusers were estimated with mixed-effects repeatedmeasures models of unstructured-variance-covariance matrix, which included data from all visits during the 5 years of followup. The model adjusted for baseline cognition, ChEI treatment (yes/no), visit time (year), and a product of ChEI treatment and visit time. Visit time had a strong nonlinear (approximately quadratic) relation with MMSE score $(p<0.05)$, so we also included a quadratic of time in the adjusted model to consider a nonlinear trend in MMSE score across time. Missing data were handled with the use of multiple imputation with chained equations in further sensitivity analysis. We in addition considered the potential effects of general attrition from those lost to follow-up due to dropout or to the presence of a competing risk before the end of follow-up such as death. We compared the cognitive trajectories between $\mathrm{ChEI}$ users and nonusers with 3 approaches: (1) mixed-effect model in real data; (2) multiple imputations, leveraging auxiliary variables associated with MMSE score missingness, in conjunction with mixed-effect models; and (3) inverse probability of censoring weighting in conjunction with multiple imputations and mixed-effect model. This last method was developed specifically to manage attrition in the SveDem cohort. ${ }^{37}$

Incidence rates per 1,000 person-years with $95 \%$ confidence intervals (CIs) were calculated for severe dementia risk
(MMSE score $<10$ ) in patients who had >1 MMSE measurements and death (all patients). Cox proportional hazards regression was used to calculate hazard ratios (HRs) associated with ChEI and each outcome. In addition, we performed subgroup analyses by sex, age categories, type of dementia, and different comorbid conditions. Furthermore, we performed a competing-risk analysis for the outcomes of severe dementia with death as the competing risk. We modeled ChEI use as a continuous exposure for increasing doses in a cubic spline with each outcome. The analyses were also run separately on donepezil, rivastigmine, and galantamine.

All analyses were performed with R (r-project.org; R Foundation for Statistical Computing, Vienna, Austria) and Stata version 16.0 (StataCorp, College Station, TX).

\section{Data Availability}

Requests for access to the SveDem data should be addressed to the registry holder and the steering committee (svedem.se).

This study provides Class III evidence that for patients with Alzheimer dementia, ChEIs decrease long-term cognitive decline and death. Galantamine in addition decreases the risk for severe dementia.

Supplementary data are available from Dryad (tables e-1-e-5 and figures e-1 and e-2): doi.org/10.5061/dryad.2jm63xsmz.

\section{Results}

\section{Baseline Characteristics}

Figure 1 shows how the propensity score-matched cohort was assembled. Table 1 and table e- 2 show the baseline characteristics by ChEI treatment in patients with Alzheimer dementia before and after matching. Patients who were not on ChEIs were older, had lower MMSE score and more comorbid conditions such as cardiovascular disorders, and took more medications than treated patients (table e-2). Matching removed many of the significant imbalances, especially in age (standardized difference decreased from $67 \%$ to $1 \%$ ), baseline MMSE score ( $46 \%$ to $0 \%$ ), hypertension ( $29 \%$ to $0 \%$ ), congestive heart failure ( $28 \%$ to $2 \%$ ), history of atrial fibrillation ( $28 \%$ to $0 \%$ ), and prescription of $\beta$-blocker ( $26 \%$ to $1 \%$ ).

The final propensity score-matched cohort included 11,652 ChEI users and 5,826 nonusers; $62 \%$ were women with a mean age of $81.2 \pm 6.3$ years. Mean baseline MMSE score was $21.2 \pm 4.2$ points, and the most common comorbid condition was hypertension (74\%), followed by cerebrovascular disease $(17 \%)$, diabetes (16\%), atrial fibrillation (16\%), and cancer (16\%). Antihypertensive and lipid-modifying agents were highly prescribed (table 1 ). The median time between the dementia diagnosis and ChEI prescription was 2 (interquartile range 0-10, range 0-90) days. Among ChEI users, donepezil accounted for $62 \%$ prescriptions, followed by galantamine $(21 \%)$ and rivastigmine (17\%). 
Table 1 Baseline Characteristics of Patients With Alzheimer Dementia in the Propensity Score-Matched Cohort

\begin{tabular}{|c|c|c|c|c|}
\hline & $\begin{array}{l}\text { No ChEla } \\
(n=5,826)\end{array}$ & $\begin{array}{l}\text { ChEI } \\
(n=11,652)\end{array}$ & $\begin{array}{l}\text { Standardized } \\
\text { Difference, }^{\text {b } \%}\end{array}$ & $p$ Value \\
\hline Diagnosis & & & 1 & 0.49 \\
\hline Alzheimer dementia, n (\%) & $3,355(57.6)$ & $6,774(58.1)$ & & \\
\hline Mixed dementia, n (\%) & $2,471(42.4)$ & $4,878(41.9)$ & & \\
\hline Age, mean (SD), y & $81.1 \pm 6.7$ & $81.2 \pm 6.1$ & 1 & 0.38 \\
\hline Female, n (\%) & $3,593(61.7)$ & $7,191(61.7)$ & 0 & 0.96 \\
\hline MMSE baseline score, mean (SD) & $21.2 \pm 4.3$ & $21.2 \pm 4.1$ & 0 & 0.87 \\
\hline \multicolumn{5}{|l|}{ Comorbid conditions, n (\%) } \\
\hline Hypertension & $4,306(73.9)$ & $8,599(73.8)$ & 0 & 0.87 \\
\hline Diabetes & $913(15.7)$ & $1818(15.6)$ & 0 & 0.91 \\
\hline Myocardial infarction & $584(10.0)$ & $1,140(9.8)$ & 1 & 0.62 \\
\hline Congestive heart failure & $551(9.5)$ & $1,036(8.9)$ & 2 & 0.22 \\
\hline Peripheral vascular disease & $288(4.9)$ & $538(4.6)$ & 2 & 0.34 \\
\hline Cerebrovascular disease & $981(16.8)$ & $2024(17.4)$ & 1 & 0.38 \\
\hline Chronic obstructive pulmonary disease & $500(8.6)$ & $1,001(8.6)$ & 0 & 0.98 \\
\hline Renal disease & $151(2.6)$ & $266(2.3)$ & 2 & 0.21 \\
\hline Cancer & $941(16.2)$ & $1810(15.5)$ & 2 & 0.29 \\
\hline Atrial fibrillation & $933(16.0)$ & $1865(16.0)$ & 0 & 0.99 \\
\hline \multicolumn{5}{|l|}{ Medication, n (\%) } \\
\hline ACEis/ARBs & $2,613(44.9)$ & $5,230(44.9)$ & 0 & 0.97 \\
\hline$\beta$-Blocking agents & $2,470(42.4)$ & $4,884(41.9)$ & 1 & 0.54 \\
\hline Calcium channel blockers & $1756(30.1)$ & $3,477(29.8)$ & 1 & 0.68 \\
\hline Lipid-modifying agents & $2,270(39.0)$ & $4,561(39.1)$ & 0 & 0.82 \\
\hline Antipsychotics & $254(4.4)$ & $541(4.6)$ & 1 & 0.40 \\
\hline Antidepressants & $1899(32.6)$ & $3,839(32.9)$ & 1 & 0.64 \\
\hline $\begin{array}{l}\text { Propensity score probability receiving } \\
\text { ChEls treatment, mean (SD) }\end{array}$ & $0.7 \pm 0.1$ & $0.7 \pm 0.1$ & 0 & 1.00 \\
\hline
\end{tabular}

Abbreviations: $\mathrm{ACEi}=$ angiotensin-converting enzyme inhibitor; $\mathrm{ARB}=$ angiotensin receptor blocker; $\mathrm{ChEI}=$ cholinesterase inhibitors; $\mathrm{MMSE}=$ Mini-Mental State Examination.

a Cohort propensity score matched for dementia diagnosis, age, sex, MMSE baseline measurement, comorbidity (hypertension, diabetes, myocardial infarction, congestive heart failure, peripheral vascular disease, cerebrovascular disease, chronic obstructive pulmonary disease, renal disease, cancer, and atrial fibrillation), and medications (use of ACEi/ARB, $\beta$-blocking agents, calcium channel blockers, lipid-modifying agents, antipsychotics, and antidepressants).

${ }^{\mathrm{b}}$ Standardized difference is calculated by dividing the mean by the SD of the difference between treated and untreated groups.

\section{ChEl Use and Long-term Cognitive Decline}

In total, 27,199 measures of MMSE were available for analysis. The number of MMSE measurements for each patient was $1.6 \pm$ 0.9 (range 1-7); 6,802 (40\%) had >1 MMSE measurement taken during up to 5 years of follow-up. At baseline, the mean MMSE scores were 22.0 points in ChEI users and 21.9 points in nonusers. ChEI users presented with better MMSE scores at any visit compared to nonusers (0.13 MMSE points change slope; 95\% CI 0.06-0.20 for real cohort). The average yearly reduction in MMSE score was -1.62 (95\% CI -1.70 to -1.54$)$ points for users and nonusers combined. These associations were consistent throughout several sensitivity analyses (tables 2 and 3), when estimating from raw data, and when applying a multiple imputation on missing MMSE measurement and adjusting for the inverse probability weighting for dropout during follow-up. Individual ChEI drugs showed an association with higher cognition at follow-up compared to nonusers, with galantamine presenting the largest effect size (0.18 MMSE points change, 95\% CI 0.07-0.28) (table 2). There were no significant differences among different ChEIs effects on cognition $\left(p_{\text {trend }}>0.05\right)$. 
Table 2 Mixed Model Output of Estimated Cognition Trajectories Among ChEl Users and Nonusers

\begin{tabular}{|c|c|c|c|c|c|c|}
\hline & \multicolumn{6}{|c|}{ MMSE Changes, Unit } \\
\hline & \multicolumn{2}{|c|}{ PS-Matched Cohort } & \multicolumn{2}{|c|}{$\begin{array}{l}\text { PS-Matched Cohort + Multiple } \\
\text { Imputation }\end{array}$} & \multicolumn{2}{|c|}{$\begin{array}{l}\text { PS-Matched Cohort + Multiple } \\
\text { Imputation + Inverse Probability } \\
\text { Weighting }\end{array}$} \\
\hline & Coefficient & $95 \% \mathrm{Cl}$ & Coefficient & $95 \% \mathrm{Cl}$ & Coefficient & $95 \% \mathrm{Cl}$ \\
\hline \multicolumn{7}{|l|}{ ChEI user compared to nonusers } \\
\hline ChEI & $0.13^{c}$ & 0.06 to 0.20 & $0.15^{\mathrm{c}}$ & 0.08 to 0.23 & $0.21^{\mathrm{c}}$ & 0.14 to 0.27 \\
\hline Follow-up time & $-1.62^{c}$ & -1.70 to -1.54 & $-1.60^{c}$ & -1.66 to -1.53 & $-1.68^{c}$ & -1.87 to -1.49 \\
\hline \multicolumn{7}{|l|}{ Stratification by different ChEI } \\
\hline No ChEI & Ref & & Ref & & Ref & \\
\hline Donepezil & $0.14^{c}$ & 0.06 to 0.21 & $0.14^{c}$ & 0.06 to 0.21 & $0.18^{\mathrm{c}}$ & 0.11 to 0.24 \\
\hline Rivastigmine & 0.06 & -0.05 to 0.17 & 0.05 & -0.06 to 0.16 & $0.10^{\mathrm{a}}$ & 0.01 to 0.19 \\
\hline Galantamine & $0.18^{c}$ & 0.07 to 0.28 & $0.17^{\mathrm{b}}$ & 0.07 to 0.27 & $0.24^{c}$ & 0.13 to 0.34 \\
\hline$p$ Trend for different ChEls & 0.19 & & 0.20 & & 0.08 & \\
\hline MMSE change per $1 \mathrm{y}$ of follow-up & $-1.63^{c}$ & -1.71 to -1.55 & $-1.63^{c}$ & -1.71 to -1.55 & $-1.68^{c}$ & -1.86 to -1.50 \\
\hline \multicolumn{7}{|c|}{ 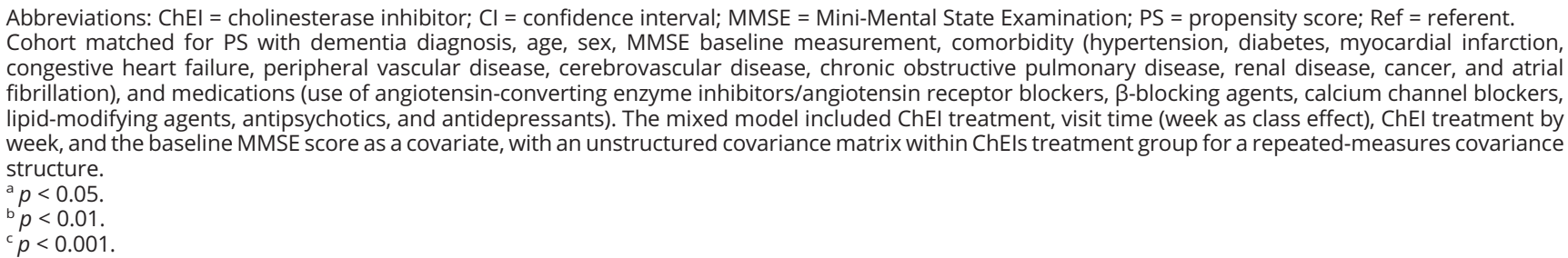 } \\
\hline
\end{tabular}

Analyses stratified by Alzheimer dementia and mixed Alzheimer dementia diagnosis did not find any marked difference in the effects of ChEI between the Alzheimer dementia group and the mixed dementia group $(0.14$ [95\% CI $0.05-0.24]$ vs 0.12 [95\% CI 0.01-0.22] MMSE points change in the Alzheimer dementia and mixed Alzheimer's dementia group, respectively) (table e-3, doi.org/10.5061/dryad.2jm63xsmz). Patients who had lower cognition at the time of diagnosis (MMSE score $<20$ ) had benefits similar to those with higher MMSE scores (0.17 [95\% CI 0.06-0.28] vs 0.10 [95\% CI $0.01-0.18]$ MMSE points change in the groups with MMSE score $<20$ and $\geq 20$, respectively) (table e- 3 ).

Figure 2A shows the dose-response effects of ChEI on cognition. Higher dispensed doses of $\mathrm{ChEI}$ were associated with higher MMSE measurements during follow-up. This association was generally observed throughout the whole range of doses considered with a modest but significant effect size. When analyses on separate ChEIs were conducted, dose response of donepezil yielded results similar to the overall $\mathrm{ChEI}$ exposure (figure e-1A, doi.org/10.5061/dryad.2jm63xsmz). Patients taking galantamine showed improved MMSE scores at follow-up, and this was significant when dispensed doses were $\geq 16 \mathrm{mg} / \mathrm{d}$ (DDD $\geq 1$ ). Although rivastigmine use was significantly associated with improved cognition (shown in table 2), a dose-response effect could not be demonstrated (figure e-1B and e-1C).

\section{ChEl and Severe Dementia Risk}

When severe dementia (MMSE score $<10$ ) was considered as the outcome, there were 6,802 patients ( $40 \%$ of the initial population) who had at least 2 MMSE measurements. The incidence rates and the proportion of patients developing severe dementia were higher among the nonusers (incidence rate $12.2 / 1,000$ person-years, $4.0 \%$ of all patients for nonusers vs $10.2 / 1,000$ person-years, $3.7 \%$ of all patients for ChEI users separately). When stratified for separate ChEIs, only galantamine users had a statistically significant lower risk of severe dementia (HR 0.69, 95\% CI 0.47-1.00), which was not significant for users of rivastigmine or donepezil or for ChEI users as a whole (table 3). Stratified analyses for the risk of severe dementia are presented in figure e-2A (doi.org/10.5061/dryad. $2 \mathrm{jm} 63 \mathrm{xsmz}$ ). Similar associations were observed for severe dementia with the competing-risk model (table e-4).

\section{ChEl and Mortality}

During an average of 5 years of follow-up, corresponding to 52,042 person-years, 6,055 (35\%) patients died. The overall mortality rate was $\approx 2$ times higher $(115.02 / 1,000$ personyears) compared with the age- and year-matched general Swedish population $(60.59 / 1,000$ person-years ) (table e-5, doi.org/10.5061/dryad.2jm63xsmz). Lower mortality rate was noted for ChEI users compared with nonusers (105.78/ 1,000 person-years vs $136.93 / 1,000$ person-years). ChEI 
Figure 2 Dose Response of ChEls Using Cubic Splines With (A) MMSE Change and (B) All-Cause Death Risk Compared With Nonuse

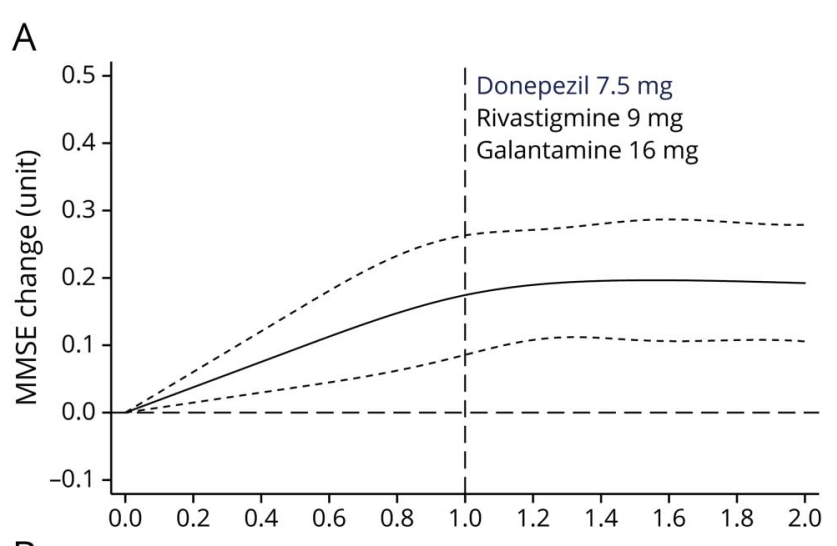

$\mathrm{B}$

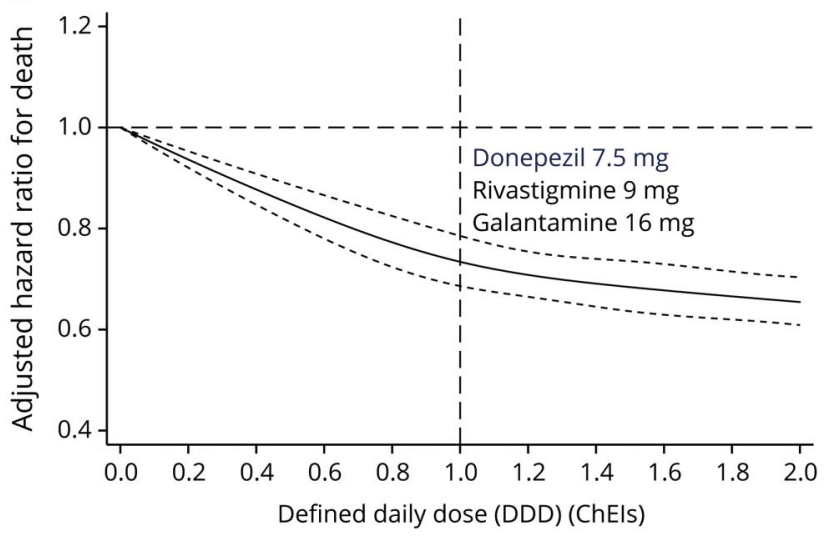

Dose-response effect of increasing average cumulative daily dose of cholinesterase inhibitor (ChEl) compared to nonuse of ChEl: average (solid) and $95 \%$ confidence interval (dash lines). Horizontal axis represents the number of standard defined daily doses (DDDs) that patients took per day. For clarity, the DDD for each medication is shown with a vertical dotted line. For example, a patient taking galantamine $8 \mathrm{mg} / \mathrm{d}$ would be taking half the DDD of galantamine, which would be represented at the 0.5 point of the horizontal axis. In panel A, y-axis represents Mini-Mental State Examination (MMSE) score change. In panel B, y-axis represents adjusted hazard ratio for death. Model included ChEl treatment, visit time (class effect), interaction of ChEl treatment by visit, and baseline MMSE score. Reference was set at DDD 0 . Cohort was matched for dementia diagnosis, age, sex, MMSE baseline score, comorbidity (hypertension, diabetes, myocardial infarction, congestive heart failure, peripheral vascular disease, cerebrovascular disease, chronic obstructive pulmonary disease, renal disease, cancer, and atrial fibrillation), and medications (angiotensin-converting enzyme inhibitors/angiotensin receptor blockers, $\beta$-blocking agents, calcium channel blockers, lipid-modifying agents, antipsychotics, and antidepressants).

users had a $27 \%$ lower risk of death (HR 0.73, 95\% CI 0.69-0.77) compared with nonusers. We observed significant differences among different ChEIs in regard to mortality risk $\left(p_{\text {trend }}<0.05\right)$, with an HR for galantamine of 0.71 (95\% CI 0.65-0.76), for donepezil of 0.78 (95\% CI 0.74-0.83), and for rivastigmine of 0.86 (95\% CI 0.80-0.93) (table 4).

There was a graded association between dispensed average DDD of ChEIs and risk of death (figure 2B). The HRs associated with increasing average DDDs of donepezil, rivastigmine, and galantamine are graphically represented in figure e-1D through e-1F (doi.org/10.5061/dryad. 2jm63xsmz). Patients who took higher dose of ChEI had lower mortality risk in a dose-dependent response. Patients taking galantamine had a lower risk of death compared with untreated patients (ratio <1) (figure e-1F).

Patients taking galantamine at any dose, $>7.5 \mathrm{mg}$ donepezil (figure e-1D), or $>9$ to $9.5 \mathrm{mg}$ rivastigmine (figure e-1E) had a lower risk of death compared with untreated patients $($ ratio $<1)$ (figure e-1F).

The associations between ChEI and death were consistent throughout all subgroup analyses (figure e-2B), albeit hampered in patients with peripheral vascular disease by lack of power. No interactions were observed between subgroup and ChEI in predicting mortality (all $p>0.05$ ).

\section{Discussion}

In this large longitudinal national dementia cohort, ChEI use was associated with a reduction in cognitive decline over time, and this effect was modest but persisted over the long term. ChEI use also was associated with reduced risk for mortality, which is in line with previous results from our group. ${ }^{27,28} \mathrm{~A}$ dose-response effect was observed for both of these outcomes. Only galantamine demonstrated a reduction in the risk for severe dementia (MMSE score $<10$ ).

Little is known about the long-term effects of ChEI on cognitive decline in Alzheimer dementia. In a 2018 Cochrane systematic review, which included 30 studies on donepezil for Alzheimer dementia, only 3 studies ${ }^{18-20}$ had a follow-up of 1 year, and only 1 study ${ }^{18}$ could be included in the meta-analysis. A recent meta-analysis ( $n=16,576$ patients with Alzheimer dementia; 63 RCTs) with an average duration of 8 months showed that although ChEIs had a benefit for cognition, the effect did not reach significant improvement. ${ }^{38}$ In the British Alzheimer's Disease 2000 study, patients with Alzheimer dementia were randomized to donepezil or placebo for 2 years. Donepezil users had 0.8 points higher MMSE scores at 2 years, but the study was underpowered and hard to interpret. ${ }^{20}$ In another study was performed in 5 Northern European countries, a significant advantage of donepezil treatment over placebo was observed at 52 weeks in cognition, activities of daily living, and the Progressive Deterioration Scale. ${ }^{18}$

The findings of our study showing significantly slower cognitive decline in patients with ChEI use are in line with results from other clinical trials. However, the magnitude of the effect appears to be somewhat smaller in our study, which is probably related to the characteristics of our cohort, the particular design, and limitations. First, we defined medication exposure within the 3 months after the dementia diagnosis, a conservative design that intended to mimic the intention-to-treat design of clinical trials and to avoid reverse causation in which the rate of cognitive decline would cause changes in medication status. Patients who were defined as treated could have stopped taking ChEIs and would still be analyzed within the 
Table 3 Estimated of Cognition Trajectories Among ChEl Users and Nonusers

\begin{tabular}{|c|c|c|c|c|c|}
\hline \multirow[b]{2}{*}{ Time of Measurement } & \multicolumn{2}{|l|}{ No ChEl } & \multicolumn{2}{|l|}{ ChEI Use } & \multirow{2}{*}{$\begin{array}{l}\text { Difference } \\
\text { Absolute } \\
\text { Difference }(95 \% \mathrm{Cl})\end{array}$} \\
\hline & $\begin{array}{l}\text { Estimated MMSE } \\
\text { Score }(95 \% \mathrm{CI})\end{array}$ & $\begin{array}{l}\text { Reduction } \\
\text { From Baseline }\end{array}$ & $\begin{array}{l}\text { Estimated MMSE } \\
\text { Score }(95 \% \mathrm{CI})\end{array}$ & $\begin{array}{l}\text { Reduction } \\
\text { From Baseline }\end{array}$ & \\
\hline \multicolumn{6}{|c|}{ Estimation from raw data } \\
\hline Baseline & $21.90(21.96-22.38)$ & - & $22.03(21.88-22.19)$ & - & 0.13 (0.06 to 0.20$)$ \\
\hline $1 y$ & $20.38(20.20-20.55)$ & -1.52 & $20.57(20.41-20.74)$ & -1.46 & 0.19 (0.11 to 0.27$)$ \\
\hline $2 y$ & 18.85 (18.64-19.06) & -3.05 & $19.11(18.93-19.29)$ & -2.92 & $0.26(0.12$ to 0.39$)$ \\
\hline $3 y$ & 17.33 (17.06-17.59) & -4.57 & $17.65(17.44-17.86)$ & -4.38 & 0.32 (0.12 to 0.52$)$ \\
\hline $4 y$ & $15.80(15.48-16.12)$ & -6.10 & 16.18 (15.94-16.43) & -5.85 & $0.38(0.12$ to 0.65$)$ \\
\hline $5 y$ & $14.27(13.89-14.66)$ & -7.63 & $14.72(14.44-15.00)$ & -7.31 & 0.45 (0.11 to 0.78$)$ \\
\hline \multicolumn{6}{|c|}{ Estimation from imputation } \\
\hline Baseline & $21.90(21.96-22.39)$ & - & $22.05(21.88-22.22)$ & - & 0.15 (0.08 to 0.23$)$ \\
\hline $1 y$ & $20.38(20.19-20.56)$ & -1.52 & $20.57(20.40-20.75)$ & -1.48 & 0.20 (0.11 to 0.28$)$ \\
\hline $2 y$ & $18.85(18.64-19.06)$ & -3.05 & 19.09 (18.90-19.28) & -2.96 & 0.24 (0.12 to 0.36$)$ \\
\hline $3 y$ & $17.33(17.08-17.58)$ & -4.57 & $17.61(17.40-17.81)$ & -4.44 & 0.28 (0.11 to 0.45$)$ \\
\hline $4 y$ & $15.80(15.51-16.10)$ & -6.10 & $16.12(15.89-16.35)$ & -5.93 & 0.32 (0.09 to 0.55$)$ \\
\hline $5 y$ & $14.28(13.93-14.63)$ & -7.62 & $14.64(14.38-14.90)$ & -7.41 & 0.36 (0.08 to 0.65$)$ \\
\hline \multicolumn{6}{|c|}{ Estimation from imputation + IPCW } \\
\hline Baseline & $21.90(21.96-22.37)$ & - & $22.11(21.94-22.28)$ & - & 0.21 (0.14 to 0.27$)$ \\
\hline $1 y$ & $20.31(20.07-20.55)$ & -1.59 & 20.49 (20.29-20.69) & -1.62 & 0.18 (0.03 to 0.33 ) \\
\hline $2 y$ & $18.72(18.34-19.10)$ & -3.18 & $18.87(18.61-19.13)$ & -3.24 & $0.15(-0.17$ to 0.47$)$ \\
\hline $3 y$ & $17.13(16.59-17.67)$ & -4.77 & $17.25(16.91-17.59)$ & -4.86 & $0.12(-0.38$ to 0.61$)$ \\
\hline $4 y$ & $15.54(14.84-16.25)$ & -6.36 & $15.63(15.20-16.06)$ & -6.48 & $0.09(-0.58$ to 0.75$)$ \\
\hline $5 y$ & $13.95(13.08-14.83)$ & -7.95 & $14.01(13.49-14.53)$ & -8.10 & $0.06(-0.79$ to 0.90$)$ \\
\hline
\end{tabular}

Abbreviations: $\mathrm{ChEI}=$ cholinesterase inhibitor; $\mathrm{Cl}$ = confidence interval; IPCW = inverse probability of censoring weighting; MMSE = Mini-Mental State Examination.

Cohort matched for propensity score with dementia diagnosis, age, sex, MMSE baseline measurement, comorbidity (hypertension, diabetes, myocardial infarction, congestive heart failure, peripheral vascular disease, cerebrovascular disease, chronic obstructive pulmonary disease, renal disease, cancer, and atrial fibrillation), and medications (use of angiotensin-converting enzyme inhibitors/angiotensin receptor blockers, $\beta$-blocking agents, calcium channel blockers, lipid-modifying agents, antipsychotics, and antidepressants). The mixed model included ChEl treatment, visit time (week as class effect), ChEI treatment by week, and the baseline MMSE score as a covariate, with an unstructured covariance matrix within ChEl treatment group for a repeatedmeasures covariance structure.

treatment group, which could naturally attenuate the difference in effect. This could not be the case for nonusers; patients who were initially nonusers who started treatment after 3 months were excluded from analyses and did not contribute follow-up time in either group. In general, patients are registered in SveDem early in the disease process. ${ }^{31}$ In our study, patients with a baseline MMSE score $>20$ declined faster than patients who started with lower MMSE scores. Second, ours is a cohort study using patients from the SveDem and naturalistic follow-ups. Attrition to follow-up was high, at $\approx 50 \%$. Third, we defined study inclusion at the date of dementia diagnosis or the date when the patient started ChEI (whichever came first); for this reason, a small proportion of patients
(6.6\% in our study) were already treated when the MMSE was performed, which would contribute to reduce the magnitude of the difference between users and nonusers.

Patients with faster cognitive decline may have higher likelihood of dropout because institutionalization, mortality, and management of the social aspects of advanced dementia probably dominate the care efforts and disrupt follow-up. Missing follow-ups would then be more frequent among severely impaired patients. This creates a situation in which patients who are followed up are more likely to start with better cognition and to decline less over time. The magnitude of the yearly decline observed in our study was -1.62 points 
Table 4 Incidence Rate and Hazard Ratios for Severe Dementia and Mortality During Follow-up

\begin{tabular}{|c|c|c|c|c|c|}
\hline & Events, $\mathrm{n}$ & Person-Time, y & IR per 1,000 py & HR $(95 \% \mathrm{Cl})$ & $p$ Value \\
\hline \multicolumn{6}{|l|}{ Severe dementia } \\
\hline No ChEI $(n=1,433)$ & 58 & 4,754 & $12.20(9.43-15.78)$ & Ref & \\
\hline $\operatorname{ChEl}^{a}(n=5,369)$ & 197 & 19,383 & $10.16(8.84-11.69)$ & $0.84(0.63-1.13)$ & 0.24 \\
\hline \multicolumn{6}{|l|}{ Separate ChEls } \\
\hline Donepezil $(n=3,131)$ & 107 & 10,692 & $10.01(8.28-12.09)$ & $0.79(0.59-1.07)$ & 0.13 \\
\hline Rivastigmine $(n=883)$ & 45 & 3,244 & $13.87(10.36-18.58)$ & $1.24(0.87-1.77)$ & 0.24 \\
\hline Galantamine $(n=1,355)$ & 45 & 5,446 & $8.26(6.17-11.07)$ & $0.69(0.47-1.00)$ & 0.05 \\
\hline$p$ Trend for different ChEls & & & & & 0.01 \\
\hline \multicolumn{6}{|l|}{ Death } \\
\hline No ChEl $(n=5,826)$ & 2,139 & 15,621 & $136.93(131.25-142.86)$ & Ref & \\
\hline ChEI $(n=11,652)$ & 3,916 & 37,021 & $105.78(102.52-109.14)$ & $0.73(0.69-0.77)$ & $<0.001$ \\
\hline \multicolumn{6}{|l|}{ Separate ChEls } \\
\hline Donepezil $(n=7,181)$ & 2,238 & 21,252 & $105.31(101.03-109.76)$ & $0.78(0.74-0.83)$ & $<0.001$ \\
\hline Rivastigmine $(n=1997)$ & 746 & 6,623 & $112.63(104.83-121.01)$ & $0.86(0.80-0.93)$ & $<0.001$ \\
\hline Galantamine $(n=2,474)$ & 932 & 9,145 & 101.91 (95.58-108.67) & $0.71(0.65-0.76)$ & $<0.001$ \\
\hline$p$ Trend for different ChEls & & & & & 0.01 \\
\hline
\end{tabular}

Abbreviations: $\mathrm{ChEI}=$ cholinesterase inhibitor; $\mathrm{Cl}=$ confidence interval; $\mathrm{HR}=$ hazard ratio; $\mathrm{IR}=$ incidence rate; py =person-year; Ref = referent.

Cohort matched for dementia diagnosis, age, sex, Mini-Mental State Examination baseline measurement, comorbidity (hypertension, diabetes, myocardial infarction, congestive heart failure, peripheral vascular disease, cerebrovascular disease, chronic obstructive pulmonary disease, renal disease, cancer, and atrial fibrillation), and medications (use of angiotensin-converting enzyme inhibitors/angiotensin receptor blockers, $\beta$-blocking agents, calcium channel blockers, lipid-modifying agents, antipsychotics, and antidepressants).

a Selected those with at least 2 MMSE measurements from matched cohort.

per year, which is in line with previous clinical trials. In the National Alzheimer's Coordinating Center study, the average decline was 1.9 points in the first year and 1.5 in the second year of follow-up. ${ }^{39}$ In the 1-year, randomized, placebo-controlled study of patients with mild to moderate $\mathrm{AD}^{18}$ the placebo group declined $\approx 2$ points per year compared to a decline of $\approx 0.5$ points per year for the donepezil users. Meanwhile, in our study, the benefit observed with ChEIs was smaller although our conservative definition of medication exposure makes it hard to directly compare these results.

ChEIs have been proven to have symptomatic effects in $\mathrm{Alz}$ heimer dementia beyond those detected by standard measures of cognition. As previously shown by our group, ChEIs have been associated with reductions in myocardial infarction, ${ }^{28}$ stroke $^{27}$ and mortality, ${ }^{27}$ while anticholinergic medications have been associated with increases in stroke and mortality risk. ${ }^{40}$ Better cognition may in itself be protective for mortality, but ChEIs also may have beneficial systemic effects. ${ }^{27,28}$ Stroke and mortality prevention in mild to moderate dementia stages is desirable, and stroke prevention could theoretically prolong independent functioning in dementia. ${ }^{41-44}$ Meanwhile, a recent study showed that initiation of antipsychotic treatment was reduced in those treated with ChEIs. ${ }^{45}$ In our study, the benefit of ChEI was similar in those diagnosed with MMSE scores <20 and those with higher MMSE scores, and the cognitive benefits persisted over time. In the Donepezil and Memantine in Moderate to Severe Alzheimer's Disease (DOMINO-AD) clinical trial, withdrawal of donepezil in patients with moderate to severe Alzheimer dementia increased the risk of nursing home placement during 12 months after treatment. ${ }^{46}$ Continuation was associated with better cognition. ${ }^{47}$ In addition, galantamine use was associated with reduced risk for severe dementia and mortality and had the largest effect size for the association with cognitive decline in our study. Galantamine is a rapidly reversible $\mathrm{ChEI}$ and the only ChEI that acts as an allosteric nicotinic modulator. $^{48,49}$ This dual effect as an acetylcholinesterase inhibitor and nicotinic receptors modulator may explain its enhanced effects.

The strengths of our study are the large sample size and long cognitive follow-up. In addition, data were obtained through standard patient registration and thus reflect real-world data. We acknowledge some limitations. First, regarding the observational study design, we cannot infer causality, and we acknowledge the possibility of residual and unknown 
confounding. However, we controlled for the unbalanced confounders in our propensity score-matching cohort. Second, patients were considered exposed throughout the whole follow-up period according to treatment status at study entry. We attempted to mimic the intention-to-treat design of clinical trials to ensure a conservative estimate of the effects of $\mathrm{ChEI}$ on cognition and because of the fear of reverse causality, in which the speed of cognitive decline could influence decisions to start or withdraw treatment. Third, we acknowledge that the vascular pathology in the group with mixed Alzheimer dementia may have affected the response to ChEI on the cognition trajectories. If anything, this may have contributed to an underestimation of the effects of the ChEI presented in this study. In addition, individual patient information on reasons for prescription or side effects of $\mathrm{ChEI}$ and information on the dispensation form of the ChEI were not available. Fourth, the national coverage of SveDem is not absolute, and there is no clear count of how many patients develop dementia each year in Sweden. On the basis of different approximations of dementia incidence and prevalence, the coverage of SveDem for new dementia cases is estimated to be between $30 \%$ and $43 \%$, depending on different estimations of incident cases regardless of whether they receive a diagnosis. ${ }^{50}$ The dementia diagnostic workup follows standard clinical practice, and few patients have a changed dementia diagnosis at follow-up, ${ }^{31}$ which suggests adequate diagnostic accuracy. Fifth, although the majority of patients are diagnosed early in the dementia disease process, some patients are diagnosed in a later stage, resulting in a variation of cognitive functioning at the time of the initiation of ChEI treatment. Finally, because our data were collected in real-world clinical practice, there were differences in the number of MMSE measurements performed between individuals, and these MMSE measurements were not missing at random; however, we attempted to address the potential concern of dropout by adjusting the estimates using inverse probability of censoring weighting. Results with and without adjusted weighting were similar and robust.

ChEIs are associated with cognitive benefits that are modest but persist over the long term. ChEIs are associated with reduced mortality risk, which may be partly explained by the modest cognitive effects. Galantamine was the only ChEI that demonstrated a significant reduction in the risk of developing severe dementia, in addition to presenting the strongest effect on cognition.

\section{Acknowledgment}

The authors are grateful to the SveDem (svedem.se) for providing data for this study. They thank all patients, caregivers, reporting units, and coordinators in SveDem, as well as the SveDem steering committee.

\section{Study Funding}

SveDem is supported financially by the Swedish Associations of Local Authorities and Regions. This study was supported by the regional agreement on medical training and clinical research between the Stockholm county council and the
Karolinska Institutet (ALF); Swedish medical research council grant 2016-02317, FORTE grant 2017-01646, Johanniterorden i Sverige/Swedish Order of St. John; and Swedish Society for Medical Research. H. Xu is supported by a postdoctoral grant from StratNeuro (the Strategic Research Area Neuroscience-Karolinska Institutet, Umeå University, and KTH). S. Garcia-Ptacek is supported by a postdoctoral fellowship from the Swedish Society for Medical Research.

\section{Disclosure}

The authors report no disclosures relevant to the manuscript. Go to Neurology.org/N for full disclosures.

\section{Publication History}

Received by Neurology April 8, 2020. Accepted in final form January 4, 2021.

\begin{tabular}{|c|c|c|}
\hline Name & Location & Contribution \\
\hline $\begin{array}{l}\text { Hong Xu, MD, } \\
\text { PhD }\end{array}$ & $\begin{array}{l}\text { Karolinska } \\
\text { Institutet, } \\
\text { Stockholm, } \\
\text { Sweden }\end{array}$ & $\begin{array}{l}\text { Design and conceptualized study; } \\
\text { analyzed the data; performed the } \\
\text { statistical analysis; drafted the } \\
\text { manuscript for intellectual } \\
\text { content }\end{array}$ \\
\hline $\begin{array}{l}\text { Sara Garcia- } \\
\text { Ptacek, MD, } \\
\text { PhD }\end{array}$ & $\begin{array}{l}\text { Karolinska } \\
\text { Institutet, } \\
\text { Stockholm, } \\
\text { Sweden }\end{array}$ & $\begin{array}{l}\text { Design and conceptualized study; } \\
\text { major role in the acquisition of } \\
\text { data; performed the statistical } \\
\text { analysis; contributed to drafting } \\
\text { the manuscript; revised the } \\
\text { manuscript for intellectual } \\
\text { content }\end{array}$ \\
\hline $\begin{array}{l}\text { Linus } \\
\text { Jönsson, MD, } \\
\text { PhD }\end{array}$ & $\begin{array}{l}\text { Karolinska } \\
\text { Institutet, } \\
\text { Stockholm, } \\
\text { Sweden }\end{array}$ & $\begin{array}{l}\text { Interpreted the data; revised the } \\
\text { manuscript for intellectual } \\
\text { content }\end{array}$ \\
\hline $\begin{array}{l}\text { Anders } \\
\text { Wimo, MD, } \\
\text { PhD }\end{array}$ & $\begin{array}{l}\text { Karolinska } \\
\text { Institutet, } \\
\text { Stockholm, } \\
\text { Sweden }\end{array}$ & $\begin{array}{l}\text { Interpreted the data; revised the } \\
\text { manuscript for intellectual } \\
\text { content }\end{array}$ \\
\hline $\begin{array}{l}\text { Peter } \\
\text { Nordström, } \\
\text { MD, PhD }\end{array}$ & $\begin{array}{l}\text { Umeå University, } \\
\text { Sweden }\end{array}$ & $\begin{array}{l}\text { Interpreted the data; revised the } \\
\text { manuscript for intellectual } \\
\text { content }\end{array}$ \\
\hline $\begin{array}{l}\text { Maria } \\
\text { Eriksdotter, } \\
\text { MD, PhD }\end{array}$ & $\begin{array}{l}\text { Karolinska } \\
\text { Institutet, } \\
\text { Stockholm, } \\
\text { Sweden }\end{array}$ & $\begin{array}{l}\text { Design and conceptualized study; } \\
\text { acquisition of data; funding; } \\
\text { revised the manuscript for } \\
\text { intellectual content; director of } \\
\text { SveDem }\end{array}$ \\
\hline
\end{tabular}

\section{References}

1. Nichols E, Szoeke CEI, Vollset SE, et al. Global, regional, and national burden of Alzheimer's disease and other dementias, 1990-2016: a systematic analysis for the Global Burden of Disease Study 2016. Lancet Neurol 2019;18:88-106.

2. Birks JS, Harvey RJ. Donepezil for dementia due to Alzheimer's disease. Cochrane Database Syst Rev 2018;6:CD001190.

3. Birks JS, Grimley Evans J. Rivastigmine for Alzheimer's disease. Cochrane database Syst Rev 2015:Cd001191.

4. Jelic V, Winblad B. Alzheimer disease. Donepezil and nursing home placement: benefits and costs. Nat Rev Neurol 2016;12:11-13.

5. Winblad B, Black SE, Homma A, et al. Donepezil treatment in severe Alzheimer's disease: a pooled analysis of three clinical trials. Curr Med Res Opin 2009;25: $2577-2587$.

6. Winblad B, Kilander L, Eriksson S, et al. Donepezil in patients with severe Alzheimer's disease: double-blind, parallel-group, placebo-controlled study. Lancet 2006;367: 1057-1065. 
7. Schmidt R, Hofer E, Bouwman FH, et al. EFNS-ENS/EAN guideline on concomitant use of cholinesterase inhibitors and memantine in moderate to severe Alzheimer's disease. Eur J Neurol 2015;22:889-898.

8. Tariot PN, Farlow MR, Grossberg GT, et al. Memantine treatment in patients with moderate to severe Alzheimer disease already receiving donepezil: a randomized controlled trial. JAMA 2004;291:317-324.

9. Porsteinsson AP, Grossberg GT, Mintzer J, Olin JT; Memantine MEM-MD-12 Study Group. Memantine treatment in patients with mild to moderate Alzheimer's disease already receiving a cholinesterase inhibitor: a randomized, double-blind, placebocontrolled trial. Curr Alzheimer Res 2008;5:83-89.

10. Howard R, McShane R, Lindesay J, et al. Donepezil and memantine for moderate-tosevere Alzheimer's disease. N Engl J Med 2012;366:893-903.

11. Grossberg GT, Manes F, Allegri RF, et al. The safety, tolerability, and efficacy of once-daily memantine $(28 \mathrm{mg})$ : a multinational, randomized, double-blind, placebocontrolled trial in patients with moderate-to-severe Alzheimer's disease taking cholinesterase inhibitors. CNS Drugs 2013;27:469-478.

12. Religa D, Fereshtehnejad SM, Cermakova P, et al. SveDem, the Swedish Dementia Registry: a tool for improving the quality of diagnostics, treatment and care of dementia patients in clinical practice. PLoS One 2015;10:e0116538.

13. Mesulam M. The cholinergic lesion of Alzheimer's disease: pivotal factor or side show? Learn Mem 2004;11:43-49.

14. Bartus RT. On neurodegenerative diseases, models, and treatment strategies: lessons learned and lessons forgotten a generation following the cholinergic hypothesis. Exp Neurol 2000;163:495-529.

15. Turnbull MT, Boskovic Z, Coulson EJ. Acute down-regulation of BDNF signaling does not replicate exacerbated amyloid-beta levels and cognitive impairment induced by cholinergic basal forebrain lesion. Front Mol Neurosci 2018;11:51.

16. Teipel SJ, Cavedo E, Hampel H, Grothe MJ. Basal forebrain volume, but not hippocampal volume, is a predictor of global cognitive decline in patients with Alzheimer's disease treated with cholinesterase inhibitors. Front Neurol 2018;9:642.

17. Li DD, Zhang YH, Zhang W, Zhao P. Meta-analysis of randomized controlled trials on the efficacy and safety of donepezil, galantamine, rivastigmine, and memantine for the treatment of Alzheimer's disease. Front Neurosci 2019;13:472.

18. Winblad B, Engedal K, Soininen H, et al. A 1-year, randomized, placebo-controlled study of donepezil in patients with mild to moderate AD. Neurology 2001;57:489-495.

19. Mohs RC, Doody RS, Morris JC, et al. A 1-year, placebo-controlled preservation of function survival study of donepezil in AD patients. Neurology 2001;57:481-488.

20. Courtney C, Farrell D, Gray R, et al. Long-term donepezil treatment in 565 patients with Alzheimer's disease (AD2000): randomised double-blind trial. Lancet 2004;363:2105-2115.

21. Karaman Y, Erdoğan F, Köseoğlu E, Turan T, Ersoy AÖ. A 12-month study of the efficacy of rivastigmine in patients with advanced moderate Alzheimer's disease. Demen Geriatr Cogn Disord 2005;19:51-56

22. Farlow M, Anand R, Messina J Jr, Hartman R, Veach J. A 52-week study of the efficacy of rivastigmine in patients with mild to moderately severe Alzheimer's disease. Eur Neurol 2000;44:236-241.

23. Vellas B, Hausner L, Frolich L, et al. Progression of Alzheimer disease in Europe: data from the European ICTUS study. Curr Alzheimer Res 2012;9:902-912.

24. Wallin AK, Andreasen N, Eriksson S, et al. Donepezil in Alzheimer's disease: what to expect after 3 years of treatment in a routine clinical setting. Demen Geriatr Cogn Disord 2007;23:150-160.

25. Wattmo C, Londos E, Minthon L. Longitudinal associations between survival in Alzheimer's disease and cholinesterase inhibitor use, progression, and communitybased services. Demen Geriatr Cogn Disord 2015;40:297-310.

26. Wattmo C, Londos E, Minthon L. Short-term response to cholinesterase inhibitors in Alzheimer's disease delays time to nursing home placement. Curr Alzheimer Res 2018;15:905-916.

27. Tan ECK, Johnell K, Garcia-Ptacek S, et al. Acetylcholinesterase inhibitors and risk of stroke and death in people with dementia. Alzheimers Dement 2018;14:944-951.

28. Nordström P, Religa D, Wimo A, Winblad B, Eriksdotter M. The use of cholinesterase inhibitors and the risk of myocardial infarction and death: a nationwide cohort study in subjects with Alzheimer's disease. Eur Heart J 2013;34:2585-2591.

29. Lin YT, Wu PH, Chen CS, Yang YH, Yang YH. Association between acetylcholinesterase inhibitors and risk of stroke in patients with dementia. Sci Rep 2016;6:29266.
30. Wattmo C, Londos E, Minthon L. Response to cholinesterase inhibitors affects lifespan in Alzheimer's disease. BMC Neurol 2014;14:173.

31. Garcia-Ptacek S, Farahmand B, Kareholt I, Religa D, Cuadrado ML, Eriksdotter M. Mortality risk after dementia diagnosis by dementia type and underlying factors: a cohort of 15,209 patients based on the Swedish Dementia Registry. J Alzheimers Dis 2014;41:467-477.

32. Garcia-Ptacek S, Modeer IN, Kareholt I, et al. Differences in diagnostic process, treatment and social Support for Alzheimer's dementia between primary and specialist care: results from the Swedish Dementia Registry. Age Ageing 2017;46: 314-319.

33. National Board of Health and Welfare. Nationella riktlinjer för vård och omsorg vid demenssjukdom: stöd för styrning och ledning (National guidelines for health an social care of dementia diseases: support for organization and governance). Åtta.45 Tryckeri AB; 2017.

34. World Health Organization. Defined Daily Dose: Essential Medicines and Health Products: ATC/DDD Toolkit[online]. Available at: who.int/medicines/regulation/ medicines-safety/toolkit ddd/en/. Accessed April 8, 2020.

35. Ludvigsson JF, Andersson E, Ekbom A, et al. External review and validation of the Swedish national inpatient register. BMC Public Health 2011;11:450.

36. National Institute for Health and Care Excellence. National Institute for Health and Care Excellence: Clinical Guidelines: Dementia: Assessment, Management and Support for People Living With Dementia and Their Carers. National Institute for Health and Care Excellence; 2018.

37. Handels R, Jonsson L, Garcia-Ptacek S, Eriksdotter M, Wimo A. Controlling for selective dropout in longitudinal dementia data: application to the SveDem registry. Alzheimers Dement 2020;16:789-796.

38. Blanco-Silvente L, Castells X, Garre-Olmo J, et al. Study of the strength of the evidence and the redundancy of the research on pharmacological treatment for $\mathrm{Alz}$ heimer's disease: a cumulative meta-analysis and trial sequential analysis. Eur J Clin Pharmacol 2019;75:1659-1667.

39. Haaksma ML, Calderon-Larranaga A, Olde Rikkert MGM, Melis RJF, Leoutsakos JS Cognitive and functional progression in Alzheimer disease: a prediction model of latent classes. Int J Geriatr Psychiatry 2018;33:1057-1064.

40. Tan ECK, Eriksdotter M, Garcia-Ptacek S, Fastbom J, Johnell K. Anticholinergic burden and risk of stroke and death in people with different types of dementia. J Alzheimers Dis 2018;65:589-596.

41. Subic A, Cermakova P, Norrving B, et al. Management of acute ischaemic stroke in patients with dementia. J Intern Med 2017;281:348-364.

42. Subic A, Zupanic E, von Euler M, et al. Stroke as a cause of death in death certificates of patients with dementia: a cohort study from the Swedish Dementia Registry. Curr Alzheimer Res 2018;15:1322-1330.

43. Garcia-Ptacek S, Contreras Escamez B, Zupanic E, et al. Prestroke mobility and dementia as predictors of stroke outcomes in patients over 65 years of age: a cohort study from the Swedish dementia and stroke registries. J Am Med Dir Assoc 2018;19:154-161.

44. Subic A, Cermakova P, Religa D, et al. Treatment of atrial fibrillation in patients with dementia: a cohort study from the Swedish Dementia Registry. J Alzheimers Dis 2018 61:1119-1128.

45. Tan ECK, Johnell K, Bell JS, et al. Do acetylcholinesterase inhibitors prevent or delay psychotropic prescribing in people with dementia? Analyses of the Swedish Dementia Registry. Am J Geriatr Psychiatry 2020;28:108-117.

46. Howard R, McShane R, Lindesay J, et al. Nursing home placement in the Donepezil and Memantine in Moderate to Severe Alzheimer's Disease (DOMINO-AD) trial: secondary and post-hoc analyses. Lancet Neurol 2015;14:1171-1181.

47. Knapp M, King D, Romeo R, et al. Cost-effectiveness of Donepezil and Memantine in Moderate to Severe Alzheimer's disease (the DOMINO-AD trial). Int J Geriat Psychiatry 2017;32:1205-1216.

48. Darreh-Shori T, Soininen H. Effects of cholinesterase inhibitors on the activities and protein levels of cholinesterases in the cerebrospinal fluid of patients with Alzheimer's disease: a review of recent clinical studies. Curr Alzheimer Res 2010;7:67-73.

49. Ago Y, Koda K, Takuma K, Matsuda T. Pharmacological aspects of the acetylcholinesterase inhibitor galantamine. J Pharmacol Sci 2011;116:6-17.

50. SveDem. Svenska Demensregistret-Årsrapport 2018 (Swedish Dementia RegistryYearly Report 2018). SveDem; 2018 


\section{Neurology}

\section{Long-term Effects of Cholinesterase Inhibitors on Cognitive Decline and Mortality}

Hong Xu, Sara Garcia-Ptacek, Linus Jönsson, et al.

Neurology 2021;96; e2220-e2230 Published Online before print March 19, 2021

DOI 10.1212/WNL.0000000000011832

This information is current as of March 19, 2021

\section{Updated Information \& Services}

References

Citations

Subspecialty Collections

Permissions \& Licensing

Reprints including high resolution figures, can be found at: http://n.neurology.org/content/96/17/e2220.full

This article cites 45 articles, 3 of which you can access for free at: http://n.neurology.org/content/96/17/e2220.full\#ref-list-1

This article has been cited by 3 HighWire-hosted articles: http://n.neurology.org/content/96/17/e2220.full\#\#otherarticles

This article, along with others on similar topics, appears in the following collection(s):

\section{Alzheimer's disease}

http://n.neurology.org/cgi/collection/alzheimers_disease

\section{Class III}

http://n.neurology.org/cgi/collection/class_iii

Cohort studies

http://n.neurology.org/cgi/collection/cohort_studies

Information about reproducing this article in parts (figures,tables) or in its entirety can be found online at:

http://www.neurology.org/about/about_the_journal\#permissions

Information about ordering reprints can be found online:

http://n.neurology.org/subscribers/advertise

Neurology ${ }^{\circledR}$ is the official journal of the American Academy of Neurology. Published continuously since 1951, it is now a weekly with 48 issues per year. Copyright Copyright ( 2021 The Author(s). Published by Wolters Kluwer Health, Inc. on behalf of the American Academy of Neurology.. All rights reserved. Print ISSN: 0028-3878. Online ISSN: 1526-632X.

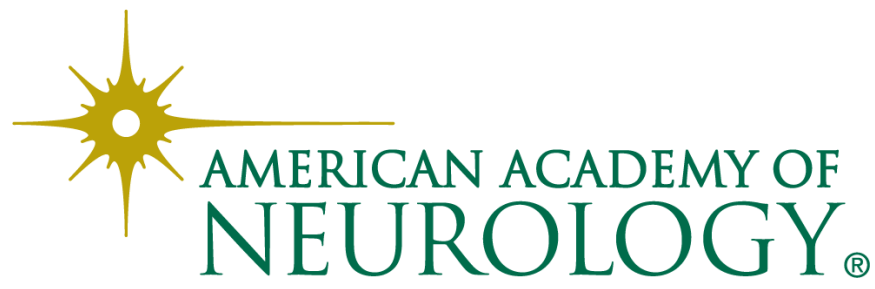

